\title{
The epidemiology of traumatic cervical spine fractures: a prospective population study from Norway
}

Hege Linnerud Fred $\varnothing^{1 *}$, Syed Ali Mujtaba Rizvi ${ }^{2}$ Bjarne Lied ${ }^{1}$, Pål Rønning ${ }^{3}$ and Eirik Helseth ${ }^{1,2}$

\begin{abstract}
Aim: The aim of this study was to estimate the incidence of traumatic cervical spine fractures (CS-fx) in a general population.

Background: The incidence of CS-fx in the general population is largely unknown.

Methods: All CS-fx (CO/C1 to C7/Th1) patients diagnosed with cervical-CT in Southeast Norway (2.7 million inhabitants) during the time period from April 27, 2010-April 26, 2011 were prospectively registered in this observational cohort study.
\end{abstract}

Results: Over a one-year period, 319 patients with CS-fx at one or more levels were registered, constituting an estimated incidence of 11.8/100,000/year. The median age of the patients was 56 years (range 4-101 years), and $68 \%$ were males. The relative incidence of CS-fx increased significantly with age. The trauma mechanisms were falls in $60 \%$, motorized vehicle accidents in $21 \%$, bicycling in $8 \%$, diving in $4 \%$ and others in $7 \%$ of patients. Neurological status was normal in 79\%, 5\% had a radiculopathy, $8 \%$ had an incomplete spinal cord injury (SCl), 2\% had a complete $\mathrm{SCl}$, and neurological function could not be determined in $6 \%$. The mortality rates after 1 and 3 months were 7 and 9\%, respectively. Among 319 patients, 26.6\% were treated with open surgery, 68.7\% were treated with external immobilization with a stiff collar and $4.7 \%$ were considered stable and not in need of any specific treatment. The estimated incidence of surgically treated CS-fx in our population was 3.1/100,000/year.

Conclusions: This study estimates the incidence of traumatic CS-fx in a general Norwegian population to be 11.8/ 100,000/year. A male predominance was observed and the incidence increased with increasing age. Falls were the most common trauma mechanism, and SCI was observed in 10\%. The 1- and 3-month mortality rates were 7 and $9 \%$, respectively. The incidence of open surgery for the fixation of CS-fx in this population was 3.1/100,000/year.

Level of evidence: This is a prospective observational cohort study and level II-2 according to US Preventive Services Task Force.

Keywords: Cervical vertebrae, Spinal fractures, Trauma, Incidence, Epidemiology

\section{Background}

The incidence of traumatic cervical spine fractures (CS-fx) in the general population is largely unknown. Several reports describe the incidence of CS-fx in different subpopulations, such as trauma center patients, specific age groups, head injury patients, military populations and osteoporotic patients [1-15]. Our literature search

\footnotetext{
* Correspondence: UXEGFR@ous-hf.no

'Department of Neurosurgery, Oslo University Hospital-Ullevål, Oslo N-0407, Norway

Full list of author information is available at the end of the article
}

identified only one article describing the incidence of spine fractures in a general population. In 1996, Hu et al. reported the incidence of spine fractures, all sites, to be $64 / 100,000$ [16]. However, subgrouping into cervical, thoracic or lumbar fractures was performed for only $45 \%$ of the patients. The assumed incidence of CS-fx can be estimated to be $12 / 100,000$ based on this study, which was performed on a population in Canada.

CS-fx are more common in males than females [1,4-6,10,11,13,17-21]. With respect to age, the highest incidence rate is reported to be among patients aged 15-45

\section{Biomed Central}


years, with a second peak in those aged $65-80$ years [1,4-6,17,21-24]. Most articles report motor vehicle collisions to be the most frequent trauma mechanism leading to cervical spine injury, $[1,2,13,14,19,21]$ while a minority report falls as the most frequent $[10,22,23]$. The incidence of cervical spine injury in the setting of head injury has been reported to range between 1.8-9\% [4,7-9,14,15,18,25]. Conversely, the incidence of moderate to severe head injury in patients with cervical spine injury is reported to be between 18 - 40\% [1,7-9,22,23,26]. Spinal cord injury (SCI) is reported to occur in $12-50 \%$ of patients with CS-fx $[4,9,11,14,16,17,21-23]$. The relationships described between CS-fx and gender, age, trauma mechanism, head injury and SCI are based on studies of subpopulations of trauma patients and not on trauma cases from a general population. Thus, these "well-accepted" relationships may not be true for cervical spine injuries in a general population.

The main aim of this study was to determine the incidence of CS-fx in a general population. We also sought to investigate possible risk factors for CS-fx, such as gender, age and trauma mechanism. In addition, the frequencies of neurological deficit and open surgical fixation in these patients were studied.

\section{Methods}

Oslo University Hospital-Ullevål (OUS-U) is a level 1 trauma center situated in Oslo. It is the only neurosurgical trauma center for the Southeast part of Norway $(120,000$ $\mathrm{km}^{2}$ ), which has 2.70 million inhabitants. The age distribution in this population is as follows: 541,077 aged $0-15$ years, 524,546 aged $16-30$ years, 578,001 aged $31-45$ years, 520,114 aged $46-60$ years, 358,150 aged $61-75$ years, 162,750 aged $76-90$ years and 15,353 aged $>90$ years. OUS-U performs $>95 \%$ of the trauma-related neurosurgical procedures in this population, including all surgeries for cervical spine injury. There are 20 hospitals within our region with general and/or orthopedic surgeons and radiological services that refer patients with head and cervical spine injuries to us. The patients are either admitted to OUS-U for treatment or non-surgical treatment is carried out locally after consultation with the Department of Neurosurgery at OUS-U.

To determine the incidence of CS-fx in this prospective observational cohort study, we prospectively registered all CS-fx patients $(\mathrm{C} 0 / \mathrm{C} 1$ to $\mathrm{C} 7 / \mathrm{Th} 1)$ diagnosed with cervical-CT (frequently supplemented with cervical MRI) in Southeast Norway from April 27, 2010-April 26, 2011.

The following data were recorded: sex, age, anatomical level of injury, number of cervical levels injured, trauma mechanism according to ICD-10, [27] fall injuries subclassified according to the Canadian C-spine rule [12] based on the mechanism of injury (falls from $\geq 1$ meter or $\geq 5$ stairs) (yes/no), Head Injury Severity Score (HISS),
[28] ankylosing spondylitis (yes/no), concomitant thoracolumbar fracture (only patients admitted to OUS-U) (yes/no), neurological deficit at the time of diagnosis (normal, radiculopathy, incomplete spinal cord injury (SCI), complete SCI or unknown (due to severe head injury or extensive multitrauma)), primary treatment (none, external immobilization with stiff collar, open surgical fixation) and mortality 1 and 3 months after the diagnosis. Vital status (dead or alive) and time of death were determined based on the Norwegian Population Registry (Folkeregisteret) data for August 1. 2011. The two major groups of fractures were further classified, odontoid fractures according to Anderson and D'Alonzo [29] and subaxial fractures according to the Subaxial Injury Classification system (SLIC) [30].

The SLIC system is based on literature review and expert opinions, designed to describe and classify cervical spine injury. It takes into account 3 major aspects of injury; the morphology, the disco-ligamentous complex and the neurological status. In each category, points are awarded for abnormalities, more points indicate a more severe injury, and the total score leads to a recommendation for surgical or non-surgical treatment.

We registered all patients diagnosed in our health region, including patients who were just visiting on vacation or work immigrants without a Norwegian social security number. The number of patients without a Norwegian social security number was 17 (5.3\%): 11 were working in Norway, three were on vacation and three could not be located.

\section{Results}

In our defined population of 2.7 million people (Southeast Norway), we prospectively registered 319 patients with one or more CS-fx during the year of registration. This registration yielded an incidence of CS-fx of 11.8/100,000.

The median age of the patients was 56 years (range 4101 years), and 217/319 (68\%) were males (Table 1). The mean age of males was significant lower than for females $(p=0.01)$. The relative incidence of CS- $f x$ increased significantly with age (Table 2 and Figure 1).

The trauma mechanisms were falls in $60 \%$, motorized vehicle accidents in $21 \%$, bicycling in $8 \%$, diving in $4 \%$ and others in 7\% (Table 3). Fall-related injuries were subclassified according to the Canadian C-spine rule, which identified falls from $\geq 1$ meter or $\geq 5$ stairs to be responsible for the injuries among 82 patients (43\%). Patients with fallrelated injuries tended to be older, while patients injured in motorized vehicle-, bicycle- or diving accidents tended to be younger (Tables 3 and 4).

Among 319 patients, a total of 420 injured levels were identified; 81 patients (26\%) had fractures at more than one cervical level (Table 1). There were 147 high CS-fx $(\mathrm{C} 0-\mathrm{C} 2)$ and 273 subaxial $(\mathrm{C} 3-\mathrm{C} 7)$ fractures. The levels 
Table 1 Patient characteristics

\begin{tabular}{|c|c|c|}
\hline & & $\mathrm{N}(\%)$ \\
\hline All & & $319(100)$ \\
\hline \multirow[t]{2}{*}{ Sex } & Female & $102(32.0)$ \\
\hline & Male & $217(68.0)$ \\
\hline \multirow[t]{7}{*}{ Age group } & $0-15$ & $7(2.2)$ \\
\hline & $16-30$ & $49(15.4)$ \\
\hline & $31-45$ & $56(17.6)$ \\
\hline & $46-60$ & $65(20.4)$ \\
\hline & $61-75$ & $64(20.1)$ \\
\hline & $76-90$ & $65(20.4)$ \\
\hline & $91-105$ & $13(4.1)$ \\
\hline Ankylosing spondylitis & Yes & $15(4.7)$ \\
\hline \multirow[t]{5}{*}{ Number of levels injured } & 1 & $237(74.3)$ \\
\hline & 2 & $68(21.3)$ \\
\hline & 3 & $10(3.1)$ \\
\hline & 4 & $3(0.9)$ \\
\hline & 5 & $1(0.3)$ \\
\hline $\mathrm{CO}-\mathrm{C7} \mathrm{fx}$ & Total & $420(100)$ \\
\hline \multirow[t]{3}{*}{$\mathrm{C} 0-\mathrm{C} 2 \mathrm{fx}$} & $\mathrm{CO}$ & $22(5.2)$ \\
\hline & $\mathrm{C} 1$ & $27(6.4)$ \\
\hline & $C 2+C 2 / 3$ & $98(23.3)$ \\
\hline \multirow[t]{5}{*}{ C3-C7 fx } & $\mathrm{C} 3+\mathrm{C} 3 / 4$ & $25(6.0)$ \\
\hline & $C 4+C 4 / 5$ & $39(9.3)$ \\
\hline & $C 5+C 5 / 6$ & $61(14.5)$ \\
\hline & $C 6+C 6 / 7$ & $89(21.2)$ \\
\hline & $\mathrm{C} 7+\mathrm{C} 7 / \mathrm{Th} 1$ & $59(14.0)$ \\
\hline \multirow{5}{*}{$\begin{array}{l}\text { Neurological status at the time } \\
\text { of diagnosis }\end{array}$} & Normal & $252(79.0)$ \\
\hline & Root injury & $15(4.7)$ \\
\hline & Incomplete SCI & $27(8.5)$ \\
\hline & Complete SCl & $6(1.9)$ \\
\hline & Unknown & $19(6.0)$ \\
\hline \multirow[t]{5}{*}{ HISS } & No head injury & $34(10.7)$ \\
\hline & Minimal & $181(56.7)$ \\
\hline & Mild & 69 (21.6) \\
\hline & Moderate & $13(4.1)$ \\
\hline & Severe & $22(6.9)$ \\
\hline
\end{tabular}

affected most frequently were $\mathrm{C} 2$ and $\mathrm{C} 5-7$. A combined high- and subaxial fracture was observed in 17 patients. The median age for patients with $\mathrm{C} 0-\mathrm{C} 2$ fractures was 66 years (range 16-101), and 58\% were males. The median age of patients with subaxial fracture was 49 (range 4-94), and $74 \%$ were males.

Ultimately, 228 of the 319 patients included in this study were admitted to OUS-U. In this subgroup, 50 (22\%) patients had a concomitant fracture in the thoracolumbar spine.
Table 2 Age-stratified incidence rate of CS-fx in the Southeastern part of Norway with $\mathbf{2 . 7 0}$ million inhabitants

\begin{tabular}{lllll}
\hline Age group & Cs-fx $\mathbf{~} \mathbf{N})$ & Population & Incidence & $\mathbf{9 5 \%} \mathbf{C l}$ \\
\hline 0-15 years & 7 & 541,077 & 1.9 & $0.52-26.66$ \\
16-30 years & 49 & 525,546 & 9.3 & $6.89-123.35$ \\
31-45 years & 56 & 578,001 & 9.7 & $7.31-125.85$ \\
46-60 years & 65 & 520,114 & 12.5 & $9.64-159.34$ \\
61-75 years & 64 & 358,150 & 17.9 & $13.76-228.19$ \\
76-90 years & 65 & 162,750 & 39.9 & $30.79-509.22$ \\
91-105 years & 13 & 15,353 & 84.7 & $45.05-1,448.77$ \\
\hline
\end{tabular}

SCI was present in 33 patients (10\%) (Table 1). Neurological disability was significantly more frequent in subaxial fractures than in $\mathrm{C} 0-\mathrm{C} 2$ fractures (Table 5). $\mathrm{SCI}$ tended to be more frequent in younger patients (Table 6).

\section{Treatment}

Ultimately, $85(26.6 \%)$ of the patients were treated with open surgery, while 219 (68.7\%) were treated with external immobilization with a stiff collar, and 15 (4.7\%) were considered stable and not in need of any specific treatment. These results yield an estimated incidence for surgically treated CS-fx in our population of 3.1/100,000/year. The data showed that $17 / 133(12.8 \%)$ patients with $\mathrm{C} 0-\mathrm{C} 2$ fractures and 68/203 (33.5\%) with subaxial fractures underwent surgery.

A total of 61 odontoid fractures were identified. According to the Anderson and D'Alonzo classification [29] there were 35 type 2 and 26 type 3 fractures. Eleven of the odontoid fractures (18\%) were treated with open surgery; of these, 7 patients had type 2 fractures and 4 patients had type 3 fractures.

All 203 patients with subaxial injuries were classified according to SLIC [30]. Open surgical fixation was performed in 68/203 (33.5\%) patients. Of 68 patients with SLIC scores $\geq 5,55$ (81\%) were treated with open surgery

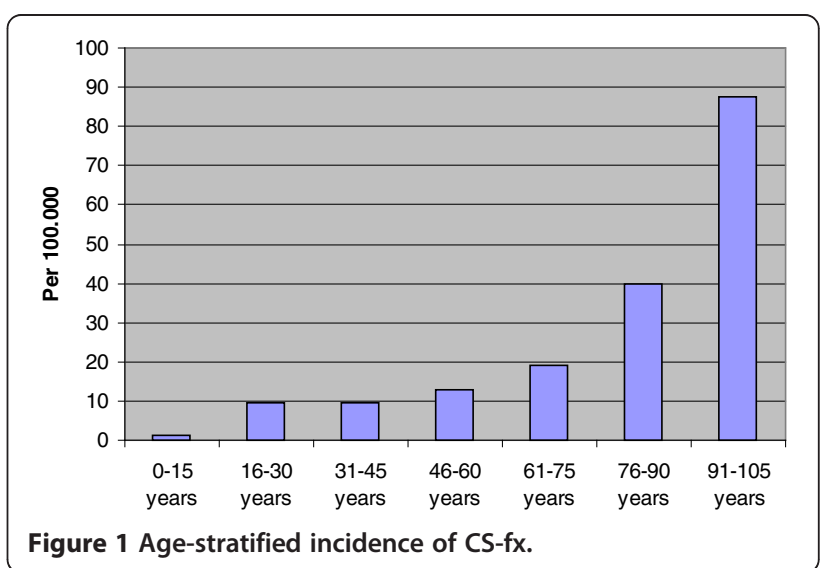


Table 3 Mechanism of trauma

\begin{tabular}{|c|c|c|c|}
\hline ICD-10 & $\mathrm{N}(\%)$ & Mean age (range) & Males N (\%) \\
\hline Falls & $190(59.6)$ & $65(12-101)$ & $124(65)$ \\
\hline \multicolumn{4}{|c|}{ won7p, wonOr, Won9r, Won5r, Won2r, Won9a, won9b, won6r, won2h } \\
\hline Motorized vehicles & $67(21.0)$ & $41(5-88)$ & $44(66)$ \\
\hline \multicolumn{4}{|c|}{$V 2 n 1 r, V 4 n 1 r, V 6 n 2 r, V 2 n 7 p, V 2 n 2 r, V 5 n 2 k$} \\
\hline Bicycle & $25(7.8)$ & $48(22-73)$ & $17(68)$ \\
\hline \multicolumn{4}{|l|}{$\operatorname{Vin} 2 p, \operatorname{Vin} 1 r$} \\
\hline Pedestrian & $4(1.3)$ & $45(37-90)$ & $3(75)$ \\
\hline \multicolumn{4}{|l|}{ VOn1r, V888r } \\
\hline Diving & $13(4.1)$ & $33(14-55)$ & $13(100)$ \\
\hline \multicolumn{4}{|l|}{ WOn8r } \\
\hline Other & $20(6.3)$ & $41(4-94)$ & $16(80)$ \\
\hline \multicolumn{4}{|c|}{ X59xy, X8n9r, W7nOr, W2s9b, W2s1r, W2s0r, W2s8p, W237p, X6nOy, X8nOr, W2s7p, W2s1p, W23xy, W231r } \\
\hline & $319(100 \%)$ & $55(4-101)$ & $217(68)$ \\
\hline
\end{tabular}

and 13 (19\%) with external immobilization. Of 27 patients with SLIC scores $=4,8$ were treated with open surgery and 19 were treated with a stiff collar. Of 108 patients with SLIC scores $<4,5$ were treated with open surgery, 94 were treated with stiff collars, and nine patients received no treatment.

\section{Mortality}

The 1 - and 3-month mortality rates in this series were 7 and $9 \%$, respectively. For surgically treated patients, the 1and 3 -month mortality rates were $2 \%$ and $3 \%$, respectively. The 3 -month mortality was $15 \%$ for patients with $\mathrm{C} 0-\mathrm{C} 2$ fractures and $6 \%$ for patients with subaxial and combined axial and subaxial fractures.

\section{Discussion}

This prospective study estimates the incidence of traumatic CS-fx in a general Norwegian population to be $11.8 / 100,000 / y e a r$. The incidence of open surgery for the fixation of CS-fx in this population is 3.1/100,000/year. Thus, $27 \%$ of the CS-fx were treated by open surgery.
We identified only one previous publication from which we could estimate the incidence of traumatic CS-fx in a general population. This Canadian study from 1996 reported the incidence of spine fractures at all sites to be $64 / 100,000 /$ year [16]. Subgrouping into cervical, thoracic or lumbar fractures was performed for only $45 \%$ of the patients that were admitted to hospitals. In these patients, the site involved was cervical in $19 \%$ of patients, thoracic in $30 \%$ of patients, lumbosacral in $43 \%$ of patients, and unspecified in $8 \%$ of patients. If we assume fractures at all levels were admitted to the same extent, this would give an incidence of CS-fx in this population of $12 / 100,000 /$ year. This incidence number is almost identical to what we find in our population.

Other authors report higher incidence numbers, but these populations are subgroups, similar to the large military population described by Schoenfeld, who found the incidence of traumatic CS-fx to be 29/100,000/year [17].

We observed a male predominance among our patient population. This is in accordance with previous reports [1,4-6,10,11,13,17-21]. The age distribution in our series

Table 4 Mechanism of trauma versus age groups

\begin{tabular}{|c|c|c|c|c|c|c|c|c|}
\hline & & \multicolumn{6}{|c|}{ ICD-10 group } & \multirow[t]{2}{*}{ Total } \\
\hline & & Falls & Motorized vehicles & Bicycle & Pedestrian & Diving & Other & \\
\hline \multirow[t]{7}{*}{ AgeGroups } & $0-15$ years & 3 & 1 & 0 & 0 & 1 & 2 & 7 \\
\hline & $16-30$ years & 16 & 21 & 3 & 0 & 4 & 5 & 49 \\
\hline & $31-45$ years & 19 & 15 & 9 & 2 & 6 & 5 & 56 \\
\hline & $46-60$ years & 40 & 9 & 9 & 1 & 2 & 4 & 65 \\
\hline & $61-75$ years & 48 & 10 & 4 & 0 & 0 & 2 & 64 \\
\hline & $76-90$ years & 52 & 11 & 0 & 1 & 0 & 1 & 65 \\
\hline & 91-105 years & 12 & 0 & 0 & 0 & 0 & 1 & 13 \\
\hline Total & & 190 & 67 & 25 & 4 & 13 & 20 & 319 \\
\hline
\end{tabular}


Table 5 Neurological status at time of diagnosis for patients with C0-C2 and subaxial fractures (fxs)

\begin{tabular}{lccc}
\hline Neurological Status & $\mathbf{C 0}-\mathbf{C 2} \mathbf{f x}(\mathbf{N}=\mathbf{1 3 3}) \mathbf{N}(\%)$ & Subaxial fx $(\mathbf{N}=\mathbf{2 0 3}) \mathbf{N}(\%)$ & Fisher's exact test \\
\hline Normal & $117(88)$ & $152(75)$ & $15(7)$ \\
Root & $0(0)$ & $22(11)$ \\
Incomplete SCl & $5(4)$ & 60.1 \\
Complete SCl & $0(0)$ & $8(4)$ & \\
Unknown & $11(8)$ & & \\
\hline
\end{tabular}

17 of the 319 patients included in this study had both C0-C2 and Subaxial Fractures (fxs). Thus, the sum of C0-C2 and Subaxial fxs in this table adds up to 336. Regarding the 17 patients with combined fxs, the charts/MRI scans were used to determine wheter the neurological deficit(s) were associated with the axial or subaxial components of the injury.

reveals the highest frequency of cervical spine fracture among those aged $46-90$ years. When adjusted for the age distribution in the Norwegian population, we found a steadily increasing incidence with rising age. This is in contrast to former reports, which found the third decade of life or age between 15-45 years to be more strongly associated with an increased risk of cervical spine injury $[1,4,5,17,21,22,24]$. Some authors also reported a second "peak" at age $65-80,[6,23,24]$ which is more in accordance with our results. We found a low incidence of cervical spine fractures in children, as reported by others $[2,3,6,15,23]$.

Fall-related injuries were observed in more than half of our patients. Most other authors have found motor vehicle collisions to be the most frequent trauma mechanism leading to cervical spine injury, with falls the second most frequent $[1,2,13,14,19,21]$. A minority of authors report the same findings that we do regarding trauma mechanism $[10,22,23]$. Minimally dangerous situations (falls from $<1$ meter or $<5$ stairs) accounted for $57 \%$ of the falls in our material. It is probable that these injuries are frequently not included in subgroups of trauma center populations. These patients are often referred from general practitioners or emergency primary care because of sustained neck pain after a minor trauma. Some recent reports indicate a trend during recent decades of an increasing median age of spine trauma patients and a shift towards falls as the most frequent mechanism of injury $[19,20]$. Our results are in line with this trend.
The incidence of cervical spine injury in patients with moderate and severe head injury has been reported to range between $1.8 \%$ and $9 \%[4,7-9,14,15,18,25,31]$. Some authors, though not all, report that patients in a trauma population with clinically significant head injuries are at greater risk of cervical spine injury than those without head trauma and that patients with a severe head injury $(\mathrm{GCS} \leq 8)$ are at even greater risk. Conversely, the incidence of moderate to severe head injury in patients with cervical spine injury is reported to be $18-40 \%$ [1,7-9,22,23,26]. In our series, $11 \%$ of the patients had a concomitant moderate or severe head injury. The lower rate of moderate and severe head injuries observed in our material is most likely because we have studied a general population and not a selected subpopulation. In contrast to many reports from selected trauma populations, we also include the low-energy trauma that often leads to cervical spine fracture in the elderly. However, the rates of minimal and mild head injury in our patients were as high as $78 \%$, so there is no doubt that head and neck injuries are closely associated.

In our patients with cervical fractures, neurological status was normal in $79 \%, 5 \%$ had a radiculopathy, $8 \%$ had incomplete SCI, $2 \%$ had complete SCI and neurological function could not be determined by chart review in $6 \%$. Neurological disability was significantly more frequent in subaxial fractures than in $\mathrm{C} 0-\mathrm{C} 2$ fractures. The incidence of cervical SCI in the setting of a cervical spine fracture is reported to be $12-50 \%[4,9,11,14,16,17,21-23]$. Only $10 \%$

Table 6 Neurological status versus age groups

\begin{tabular}{|c|c|c|c|c|c|c|c|}
\hline & & & & Neurologica & & & $\overline{\text { Total }}$ \\
\hline & & Normal & Root & Incomplete SCI & Complete SCI & Unknown & \\
\hline Age Groups & $0-15$ years & 6 & 0 & 0 & 0 & 1 & 7 \\
\hline & $16-30$ years & 39 & 3 & 1 & 2 & 4 & 49 \\
\hline & $31-45$ years & 41 & 5 & 5 & 3 & 2 & 56 \\
\hline & $46-60$ years & 51 & 5 & 4 & 0 & 5 & 65 \\
\hline & $61-75$ years & 47 & 2 & 10 & 1 & 4 & 64 \\
\hline & $76-90$ years & 57 & 0 & 5 & 0 & 3 & 65 \\
\hline & 91-105 years & 11 & 0 & 2 & 0 & 0 & 13 \\
\hline Total & & 252 & 15 & 27 & 6 & 19 & 319 \\
\hline
\end{tabular}


of the patients in our study population had SCI. Again, the lower rate of $\mathrm{SCI}$ in our report compared to other series is likely due to our study of the general population rather than a subpopulation. The incidence of cervical SCI in the setting of a CS-fx is $1.2 / 100,000 /$ year.

In a population study from Western Norway, the incidence of acute traumatic SCI during the time period from 1997-2001 was estimated to be 1.4/100,000 [32]. This study also included SCI without concurrent CS-fx.

The 1- and 3-month mortality rates in this series were 7 and $9 \%$, respectively. For surgically treated patients, the 1and 3-month mortality rates were $2 \%$ and $3 \%$, respectively.

We have not found comparable mortality data on patients with CS-fx from a general population, but according to the mortality rates reported in different subgroups, the mortality in our population seems to be in the lower range [1,4,22,33-35].

Among all 319 patients, 27\% were treated with open surgery, $68 \%$ were treated with external immobilization with a stiff collar and 5\% were considered stable and not in need of any specific treatment. This distribution yields an estimated incidence of surgically treated CS- $\mathrm{fx}$ in our population of 3.1/100,000/year.

Of the odontoid fractures, $18 \%$ were treated with open surgery, seven were type 2 fractures and four were type 3 fractures. There is still insufficient evidence to establish a standard or guideline for odontoid fracture management, and there are various reported approaches for treatment [36-38].

Open surgical fixation was conducted in $33.5 \%$ of the patients with subaxial fractures. Among patients with SLIC scores $\geq 5,81 \%$ were treated with open surgery and $19 \%$ with external immobilization. These are cases in which the SLIC recommended open surgical treatment. Among the population studied here, $37 \%$ of the patients with SLIC scores $=4$ underwent open surgery, and 63\% received a stiff collar. In this group, SLIC found the treatment options to be equivocal. The records showed that $5 \%$ of the patients with SLIC scores $<4$ were treated with open surgery, $87 \%$ were treated with stiff collars, and $8 \%$ received no treatment. The SLIC recommendation for these patients is non-surgical treatment. In this investigation, $9 \%$ of our patients with subaxial CS-fx were not treated with the modality recommended based on the SLIC score. However, concomitant and comorbidity factors are to be taken into consideration when selecting treatment, and these factors are not accounted for in the treatment algorithms used here. We therefore find our compliance with the SLIC recommendations to be acceptable.

\section{Limitations}

The incidence of CS-fx found in our study is most likely an underestimate because we believe that some fractures are considered stable at their local orthopedic departments, and they are treated with external immobilization without our knowledge. We know this for certain because some of these patients are later referred to us when the non-surgical treatment has failed. Data from The Norwegian Patient Registry also support the assumption that the present data are an underestimate (HL Fredø et al., unpublished results). Some fractures causing immediate death at the scene of the accident are also missed when using this approach. Reports suggest that $21-24 \%$ of victims dying immediately or soon after a traffic accident have a serious injury to the cervical spine $[39,40]$.

\section{Strengths}

Our data were registered prospectively in a defined general population, and the study is contemporary. All charts and radiological examinations were reviewed.

\section{Conclusions}

This prospective study estimates the incidence of traumatic CS- $\mathrm{fx}$ in a general Norwegian population to be $11.8 / 100,000 /$ year. A male predominance was observed, and the incidence increased with advancing age. Falls were the most common trauma mechanism, and SCI was observed in $10 \%$ of those included. The 1- and 3 -month mortality rates were $7 \%$ and $9 \%$, respectively. The incidence of open surgical fixation of CS-fx in this population is $3.1 / 100,000 /$ year.

\section{Competing interests \\ The authors declare that they have no conflict of interest. The authors alone are responsible for the content and writing of this paper.}

\section{Authors' contribution}

Study design: HLF and EH. Collection of data: HLF and SAMR. Data analysis and statistics: HLF, SAMR, BL, PR and EH. Interpretation of data: HLF, SAMR, $B L, P R$ and EH. Writing of manuscript: HLF, PR and EH. All authors read and approved the final manuscript.

\section{Author details}

'Department of Neurosurgery, Oslo University Hospital-Ullevål, Oslo N-0407, Norway. ${ }^{2}$ Faculty of Medicine, University of Oslo, Oslo, Norway. ${ }^{3}$ Department of Neurosurgery, Oslo University Hospital-Rikshospitalet, Oslo, Norway.

Received: 20 August 2012 Accepted: 16 December 2012 Published: 21 December 2012

\section{References}

1. Clayton JL, Harris MB, Weintraub SL, Marr AB, Timmer J, Stuke LE, et al: Risk factors for cervical spine injury. Injury 2012, 43:431-435.

2. Brown RL, Brunn MA, Garcia VF: Cervical spine injuries in children: a review of 103 patients treated consecutively at a level 1 pediatric trauma center. J Pediatr Surg 2001, 36:1107-1114.

3. Cirak B, Ziegfeld S, Knight VM, Chang D, Avellino AM, Paidas CN: Spinal injuries in children. J Pediatr Surg 2004, 39:607-612.

4. Hills MW, Deane SA: Head injury and facial injury: is there an increased risk of cervical spine injury? I Trauma 1993, 34:549-553.

5. Hoffman JR, Schriger DL, Mower W, Luo JS, Zucker M: Low-risk criteria for cervical-spine radiography in blunt trauma: a prospective study. Ann Emerg Med 1992, 21:1454-1460.

6. Lowery DW, Wald MM, Browne BJ, Tigges S, Hoffman JR, Mower WR: Epidemiology of cervical spine injury victims. Ann Emerg Med 2001, 38:12-16.

7. Michael DB, Guyot DR, Darmody WR: Coincidence of head and cervical spine injury. J Neurotrauma 1989, 6:177-189. 
8. Mulligan RP, Friedman JA, Mahabir RC: A nationwide review of the associations among cervical spine injuries, head injuries, and facial fractures. J Trauma 2010, 68:587-592.

9. O'Malley KF, Ross SE: The incidence of injury to the cervical spine in patients with craniocerebral injury. J Trauma 1988, 28:1476-1478.

10. Roberge RJ, Wears RC, Kelly M, Evans TC, Kenny MA, Daffner RD, et al: Selective application of cervical spine radiography in alert victims of blunt trauma: a prospective study. J Trauma 1988, 28:784-788.

11. Sanchez B, Waxman K, Jones T, Conner S, Chung R, Becerra S: Cervical spine clearance in blunt trauma: evaluation of a computed tomography-based protocol. J Trauma 2005, 59:179-183.

12. Stiell IG, Wells GA, Vandemheen KL, Clement CM, Lesiuk H, De Maio VJ, et al: The Canadian C-spine rule for radiography in alert and stable trauma patients. JAMA 2001, 286:1841-1848.

13. Thompson WL, Stiell IG, Clement CM, Brison RJ: Association of injury mechanism with the risk of cervical spine fractures. CJEM 2009, 11:14-22.

14. Williams J, Jehle D, Cottington E, Shufflebarger C: Head, facial, and clavicular trauma as a predictor of cervical-spine injury. Ann Emerg Med 1992, 21:719-722.

15. Yanar H, Demetriades D, Hadjizacharia P, Nomoto S, Salim A, Inaba K, et al: Pedestrians injured by automobiles: risk factors for cervical spine injuries. J Am Coll Surg 2007, 205:794-799.

16. Hu R, Mustard CA, Burns C: Epidemiology of incident spinal fracture in a complete population. Spine (Phila Pa 1976) 1996, 21:492-499.

17. Schoenfeld AJ, Sielski B, Rivera KP, Bader JO, Harris MB: Epidemiology of cervical spine fractures in the US military. Spine J, 24-4-2012. Ref Type: Electronic Citation.

18. Holly LT, Kelly DF, Counelis GJ, Blinman T, McArthur DL, Cryer HG: Cervical spine trauma associated with moderate and severe head injury: incidence, risk factors, and injury characteristics. J Neurosurg 2002, 96:285-291.

19. Jackson AB, Dijkers M, Devivo MJ, Poczatek RB: A demographic profile of new traumatic spinal cord injuries: change and stability over 30 years. Arch Phys Med Rehabil 2004, 85:1740-1748.

20. Kattail D, Furlan JC, Fehlings MG: Epidemiology and clinical outcomes of acute spine trauma and spinal cord injury: experience from a specialized spine trauma center in Canada in comparison with a large national registry. J Trauma 2009, 67:936-943.

21. McCabe JB, Angelos MG: Injury to the head and face in patients with cervical spine injury. Am J Emerg Med 1984, 2:333-335.

22. Bohlman $\mathrm{HH}$ : Acute fractures and dislocations of the cervical spine. An analysis of three hundred hospitalized patients and review of the literature. J Bone Joint Surg Am 1979, 61:1119-1142.

23. Leucht $P$, Fischer $K$, Muhr G, Mueller EJ: Epidemiology of traumatic spine fractures. Injury 2009, 40:166-172

24. Ryan MD, Henderson JJ: The epidemiology of fractures and fracture-dislocations of the cervical spine. Injury 1992, 23:38-40.

25. Soicher $E$, Demetriades D: Cervical spine injuries in patients with head injuries. Br J Surg 1991, 78:1013-1014.

26. Steudel WI, Rosenthal D, Lorenz R, Merdes W: Prognosis and treatment of cervical spine injuries with associated head trauma. Acta Neurochir Suppl 1988, 43:85-90.

27. ICD-10: International statistical classification of diseases and related health problems. Geneva: World Health Organization; 2009

28. Stein SC, Spettell C: The Head Injury Severity Scale (HISS): a practica classification of closed-head injury. Brain Inj 1995, 9:437-444.

29. Anderson LD, D'Alonzo RT: Fractures of the odontoid process of the axis. J Bone Joint Surg Am 1974, 56:1663-1674.

30. Vaccaro AR, Hulbert RJ, Patel AA, Fisher C, Dvorak M, Lehman RA Jr, et a: The subaxial cervical spine injury classification system: a novel approach to recognize the importance of morphology, neurology, and integrity of the disco-ligamentous complex. Spine 2007, 32:2365-2374

31. Bayless P, Ray VG: Incidence of cervical spine injuries in association with blunt head trauma. Am J Emerg Med 1989, 7:139-142.

32. Hagen EM, Eide GE, Rekand T, Gilhus NE, Gronning M: A 50-year follow-up of the incidence of traumatic spinal cord injuries in Western Norway. Spinal Cord 2010, 48:313-318.

33. Harris MB, Reichmann WM, Bono CM, Bouchard K, Corbett KL, Warholic N, et al: Mortality in elderly patients after cervical spine fractures. J Bone Joint Surg Am 2010, 92:567-574
34. ter Gunne AF P, Aquarius AE, Roukema JA: Risk factors predicting mortality after blunt traumatic cervical fracture. Injury 2008, 39:1437-1441.

35. Sokolowski MJ, Jackson AP, Haak MH, Meyer PR Jr, Szewczyk SM: Acute outcomes of cervical spine injuries in the elderly: atlantaxial vs subaxia injuries. J Spinal Cord Med 2007, 30:238-242

36. Julien TD, Frankel B, Traynelis VC, Ryken TC: Evidence-based analysis of odontoid fracture management. Neurosurg Focus, 8(6):e1. 24-4-2012. Ref Type: Electronic Citation.

37. Harrop JS, Hart R, Anderson PA: Optimal treatment for odontoid fractures in the elderly. Spine 2010, 35:S219-S227.

38. Rizvi SA, Fredo HL, Lied B, Nakstad PH, Ronning P, Helseth E: Surgical management of acute odontoid fractures: Surgery-related complications and long-term outcomes in a consecutive series of 97 patients. J Trauma Acute Care Surg 2012, 72:682-690

39. Alker GJ, Oh YS, Leslie EV, Lehotay J, Panaro VA, Eschner EG: Postmortem radiology of head neck injuries in fatal traffic accidents. Radiology 1975, 114:611-617.

40. Bucholz RW, Burkhead WZ, Graham W, Petty C: Occult cervical spine injuries in fatal traffic accidents. J Trauma 1979, 19:768-771.

\section{doi:10.1186/1757-7241-20-85}

Cite this article as: Fred $\varnothing$ et al:: The epidemiology of traumatic cervical spine fractures: a prospective population study from Norway.

Scandinavian Journal of Trauma, Resuscitation and Emergency Medicine 2012 20:85.

\section{Submit your next manuscript to BioMed Central and take full advantage of:}

- Convenient online submission

- Thorough peer review

- No space constraints or color figure charges

- Immediate publication on acceptance

- Inclusion in PubMed, CAS, Scopus and Google Scholar

- Research which is freely available for redistribution 